\title{
OTIMIZAÇÃO DOS PARÂMETROS OPERACIONAIS PARA AUMENTAR A RENTABILIDADE DE PROJETOS DE INJEÇÃO DE ÁGUA APÓS O VAPOR EM RESERVATÓRIOS DE ÓLEO PESADO
}

\author{
M. A. F. RODRIGUES ${ }^{1}$, E. R. V. P. GALVÃO ${ }^{1}$ \\ ${ }^{1}$ Universidade Federal do Rio Grande do Norte, Departamento de Engenharia de Petróleo \\ E-mail para contato: marcos.allyson@gmail.com
}

\begin{abstract}
RESUMO - Muitas das reservas de hidrocarbonetos existentes no mundo são formadas por óleos pesados . Entre os métodos térmicos usados para recuperar esses recursos, a injeção de vapor tem sido a principal alternativa economicamente viável. A fim de manter os níveis de produção de óleo e reduzir os custos deste método, a injeção de água tem sido utilizada junto ao vapor. Neste trabalho, foi realizada uma otimização dos parâmetros operacionais tais como vazão de vapor, vazão de água e completação do poço injetor para a produção de óleo pesado em um modelo de reservatório semissintético com características semelhantes às encontradas na Bacia Potiguar, utilizando o processo de injeção de vapor seguido por água. As respostas analisadas foram a Recuperação de óleo e o Valor Presenbte Líquido (VPL). Verificou-se, através de Superfícies de Resposta, que uma maior rentabilidade do projeto é obtida na interação entre elevados valores de vazão de injeção de vapor e completação na base do reservatório.
\end{abstract}

\section{INTRODUÇÃO}

Os processos de recuperação térmica têm sido largamente empregados na recuperação de óleos pesados, melhorando o escoamento do óleo através da redução da viscosidade e viabilizando a produção de petróleo em campos considerados inviáveis comercialmente pelos métodos convencionais de recuperação (Galvão, 2008). Dentre os vários métodos térmicos existentes, a injeção de vapor é o mais utilizado atualmente pela indústria e, em grande parte, apresenta bons resultados.

No Brasil, a injeção de vapor é o método especial de recuperação avançada mais utilizado para a extração de óleos pesados, utilizado principalmente no Nordeste onde possui muitas reservas contendo este tipo de óleo, destacando os estados Rio Grande do Norte e o Ceará.

A fim de obter uma maior recuperação de óleo e reduzir os custos inerentes à injeção de vapor, nos últimos anos a injeção de fluidos alternativos tem sido utilizada de duas formas principais: alternadamente e após a injeção de vapor. Nesses sistemas busca-se reduzir a quantidade de calor fornecida ao reservatório, injetando fluidos de menor valor comercial. Os fluidos alternativos ao vapor mais utilizados são o $\mathrm{CO}_{2}$, o gás natural e a água. 


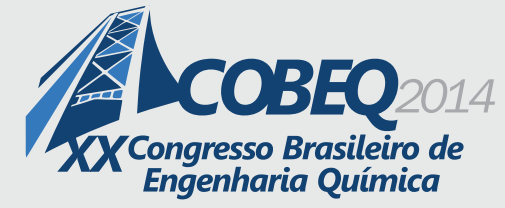

O presente trabalho tem como objetivo analisar a injeção de água após o vapor, buscando aumentar a rentabilidade de um projeto de recuperação avançada aplicada a um reservatório de óleo pesado. Foi realizada a otimização de parâmetros operacionais tais como vazão de vapor, vazão de água e a completação do poço injetor através de superfícies de resposta, com intuito de obter a configuração operacional que resulta em uma maior rentabilidade para o projeto, considerando como variável resposta o Valor Presente Líquido (VPL).

\section{METODOLOGIA}

Para o caso base, foi considerado um reservatório homogêneo de $100 \mathrm{~m}$ x $100 \mathrm{~m}$ x $28 \mathrm{~m}$ com refinamento no topo ( $25 \times 25$ x 15 blocos), como mostra a Figura 1. As simulações foram realizadas no módulo STARS da CMG 2010.10, que trabalha com métodos térmicos de recuperação de óleo.



Figura 1. Modelo base em 3 dimensões.

As principais propriedades da rocha reservatório são apresentadas na Tabela 1. Estes parâmetros são dados necessários na entrada do simulador.

Tabela 1. Propriedades da rocha-reservatório.

\begin{tabular}{cc}
\hline Temperatura inicial $\left({ }^{\circ} \mathrm{C}\right)$ & 38 \\
$(\%)$ & 35 \\
Saturação inicial média de água na zona de óleo, $\mathrm{S}_{\mathrm{wi}}$ & \\
Volume original de óleo na zona de óleo $\left(\mathrm{m}^{3} \mathrm{std}\right)$ & 36930 \\
Espessura da zona de óleo $(\mathrm{m})$ & 20 \\
Profundidade do topo do reservatório $(\mathrm{m})$ & 200 \\
Contato gás-óleo - DGOC $(\mathrm{m})$ & 202 \\
Contato água-óleo - DWOC $(\mathrm{m})$ & 222 \\
Permeabilidade horizontal, $\mathrm{k}_{\mathrm{h}}(\mathrm{md})$ & 1000 \\
Permeabilidade vertical, $\mathrm{k}_{\mathrm{v}}(\mathrm{md})$ & 100 \\
Porosidade $(\%)$ & 28 \\
\hline
\end{tabular}


O modelo do fluido do reservatório foi criado a partir de uma análise PVT. A Tabela 2 mostra a composição do óleo, que contém seis pseudo-componentes, as características da fração pesada $\mathrm{C} 40+$, o ${ }^{\circ} \mathrm{API}$ do óleo e sua pressão de saturação. Pelo ${ }^{\circ} \mathrm{API}$ pode-se dizer que o óleo é pesado, de características similares aos encontrados na Bacia Potiguar.

Tabela 2. Composição do óleo

\begin{tabular}{cc}
\hline Pseudocomponente & $\begin{array}{c}\text { Fração Molar } \\
(\mathbf{\%})\end{array}$ \\
\hline $\mathrm{CO}_{2}$ & 0,45 \\
$\mathrm{~N}_{2}$ & 0,27 \\
$\mathrm{C}_{1}-\mathrm{C}_{3}$ & 10,35 \\
$\mathrm{C}_{4}-\mathrm{C}_{19}$ & 17,35 \\
$\mathrm{C}_{20}-\mathrm{C}_{39}$ & 46,16 \\
$\mathrm{C}_{40+}$ & 25,42 \\
\hline
\end{tabular}

Características do $\mathrm{C}_{40+}$ : $\quad$ Características do óleo a $38^{\circ} \mathrm{C}$ :

Peso molecular: 823,52 u ${ }^{\circ}$ API: 16,38

Densidade relativa: 1,0305 Pressão de saturação: $2650,74 \mathrm{kPa}(384,45$ psi)

Nos métodos térmicos, em especial na injeção de vapor, o principal razão para se obter altos fatores de recuperação é a alta sensibilidade da viscosidade do óleo à temperatura. A Figura 2 mostra o comportamento da viscosidade do óleo versus temperatura para o modelo de óleo pesado estudado. Observa-se que, para a temperatura inicial do reservatório $38{ }^{\circ} \mathrm{C}\left(100^{\circ} \mathrm{F}\right)$, a viscosidade do óleo é de $1120 \mathrm{cP}$.



Figura 2. Viscosidade do óleo versus temperatura

A Tabela 3 apresenta os principais parâmetros operacionais utilizados no modelo base. 
Tabela 3. Condições operacionais do processo.

\begin{tabular}{cc}
\hline Parâmetro & Valor \\
\hline Temperatura do vapor $\left({ }^{\circ} \mathrm{C}\right)$ & 288 \\
Título do vapor $(\%)$ & 50 \\
Pressão máxima no poço injetor $(\mathrm{kPa})$ & 7198 \\
Vazão de vapor injetado $\left(\mathrm{m}^{3} \mathrm{std} / \mathrm{dia}\right)$ & variável \\
Vazão de água $\left(\mathrm{m}^{3} \mathrm{std} / \mathrm{dia}\right)$ & variável \\
Distância entre poços injetor-produtor & 140 \\
$(\mathrm{~m})$ & \\
Intervalo canhoneado & Toda a Zona de Óleo \\
Tempo de injeção de vapor (anos) & 11 \\
Tempo de injeção de água (anos) & 5 \\
Tempo de projeto (anos) & 16 \\
\hline
\end{tabular}

O tempo de injeção de vapor e água foi adotado com base no estudo de Rodrigues (2012). Neste trabalho foi realizada uma variação da vazão de injeção vapor, vazão de água além da completação do poço injetor em valores conforme a Tabela 4.

Tabela 4. Parâmetros operacionais e o intervalo estudado na injeção de vapor e água.

\begin{tabular}{lccc}
\hline \multicolumn{1}{c}{ Parâmetro } & $\begin{array}{c}\text { Valor mínimo } \\
(-1)\end{array}$ & $\begin{array}{c}\text { Valor intermediário } \\
(0)\end{array}$ & $\begin{array}{c}\text { Valor máximo } \\
(+1)\end{array}$ \\
\hline Vazão de injeção de vapor (t/dia) & 12,5 & 25 & 37,5 \\
Vazão de injeção de água $\left(\mathrm{m}^{3} / \mathrm{dia}\right)$ & 12,5 & 25 & 37,5 \\
Completação do poço injetor & centro & Todo intervalo & base
\end{tabular}

Para o cálculo do Valor Presente Líquido (VPL) foi utilizada a Equação 1, considerando diversos custos envolvidos no processo. A Equação 1 foi desenvolvida com o objetivo de realizar uma análise econômica, através do VPL, para as configurações operacionais estudadas. A ideia principal é ter uma ferramenta decisória para avaliar economicamente as diversas alternativas apresentadas, buscando as mais rentáveis.

$V P L=\sum_{i=1}^{n}\left[\frac{\left(R-C_{\mathrm{gm}}-C_{\mathrm{gl}}-\epsilon_{\text {agua }}-F_{\text {gavernamental- }} C_{\text {agua }-\mathrm{in} j}\right.}{(1+i)^{n}}\right]-C_{a}-C_{p}$

(Equação 1)

Onde:

Onde $\mathrm{R}$ é a Receita gerada pela comercialização do óleo; $\mathrm{C}_{\mathrm{om}}$ é o custo de operação e manutenção do gerador; $\mathrm{C}_{\mathrm{el}}$ é o custo de elevação dos fluidos; $\mathrm{C}_{\text {oleo }}$ é o custo de transporte, separação e tratamento do óleo; $\mathrm{C}_{\text {agua }}$ é o custo de separação, tratamento e descarte da água produzida; $\mathrm{C}_{\text {governamental }}$ é a Participação governamental (impostos); $\mathrm{C}_{\text {agua-inj }}$ é o custo da água injetada; i é a taxa mínima de atratividade e n é o tempo de projeto 
A Tabela 5 apresenta um quadro resumo dos valores considerados para a análise técnicoeconômica e utilizados na Equação 1, obtidos do estudo de Rodrigues (2012).

Tabela 5. Dados considerados para a análise de viabilidade técnica-econômica

\begin{tabular}{|c|c|}
\hline Dados & Valor \\
\hline Preço de aquisição do gerador de vapor (US\$) & $1.200 .000,00$ \\
\hline Custo de Perfuração e completação de um poço vertical onshore (US\$/poço) & $400.000,00$ \\
\hline Participacão governamental (\% da receita bruta) & 20 \\
\hline Custo de elevação de fluidos (US\$/bblóleo) & 5,00 \\
\hline Custo de separação, tratamento e descarte da água produzida $\left(\mathrm{US} \$ / \mathrm{m}^{3}\right)$ & 3,00 \\
\hline Custo de transporte, separação e tratamento do óleo (US\$/bblóleo $)$ & 1,00 \\
\hline Custo de operação e manutenção do gerador (US\$/ bblóleo) & 10,00 \\
\hline Custo da água injetada (US $\left.\$ / \mathrm{m}^{3}\right)$ & 2,00 \\
\hline Preco do petróleo (US\$/bbl) & 50 \\
\hline Tempo de projeto (anos) & 16 \\
\hline TMA (\% a.a.) & 15 \\
\hline
\end{tabular}

Para realizar a otimização dos parâmetros operacionais no desempenho do processo da injeção de vapor e água para o modelo de reservatório proposto, os parâmetros assim como os intervalos estudados estão apresentados na Tabela 4.

\section{RESULTADOS E DISCUSSÕES}

A Figura 3 apresenta as Superfícies de Resposta para o Valor Presente Líquido (VPL) para a interação da vazão de injeção de vapor com a vazão de água e intervalo canhoneado, considerando o final do projeto.
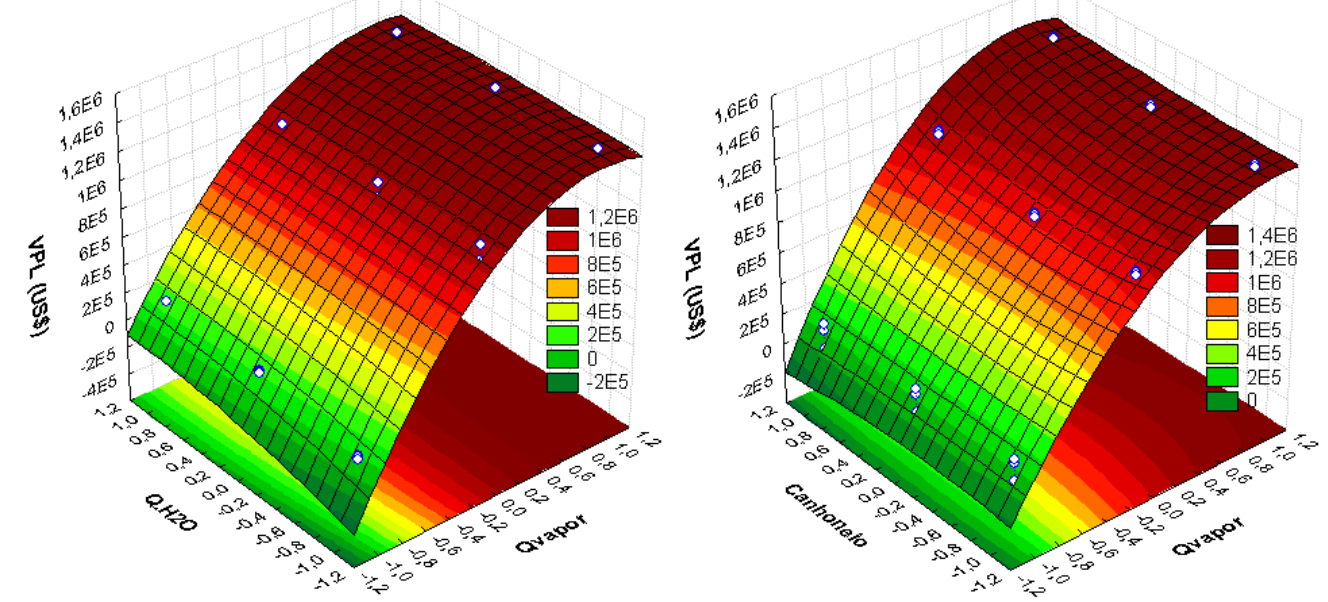

Figura 3. Superfícies de resposta da interação da vazão de injeção de vapor (Qvapor) com a vazão de água (Q.H2O) e o intervalo canhoneado respectivamente - Valor Presente Líquido. 
Quando se analisa o Valor Presente Líquido (VPL) neste sistema e considerando a interação vazão de injeção de vapor e de água, pode ser observado que a resposta é favorecida quando a vazão de vapor está em torno do nível mais alto $(37.5$ t/dia (+1)) para qualquer nível de vazão de água. No caso da interação vazão de injeção de vapor (Qvapor) e intervalo canhoneado (Canhoneio), tem-se o máximo da função objetivo alcançado quando se tem a vazão de vapor em torno do nível mais alto $(37,5 \mathrm{t} /$ dia $(+1))$ e intervalo canhoneado no nível mais alto (base $(+1)$ ).

A Figura 4 mostra os resultados obtidos em termos de Valor Presente Líquido para o estudo da injeção de água após 11 anos de vapor, mantendo fixa a vazão de água em 25 $\mathrm{m}^{3} \mathrm{std} /$ dia. Podem ser observados três grupos de curvas distintos, cada um com 3 resultados, determinado pela vazão de vapor utilizada. Os tempos de retorno do investimento são determinados pela atuação do vapor no reservatório. Para a vazão de 37,5 t/dia o tempo de retorno se dá entre o quarto e o quinto ano, sendo que quando o canhoneio foi realizado na base do reservatório ocorreu uma pequena antecipação de receitas. Para a vazão de $25 \mathrm{t} / \mathrm{dia}$ tem-se o payback entre o sexto e o sétimo ano de projeto e quando a vazão foi de 12,5 t/dia ocorreu entre o $12^{\circ}$ e o $13^{\circ}$ ano.

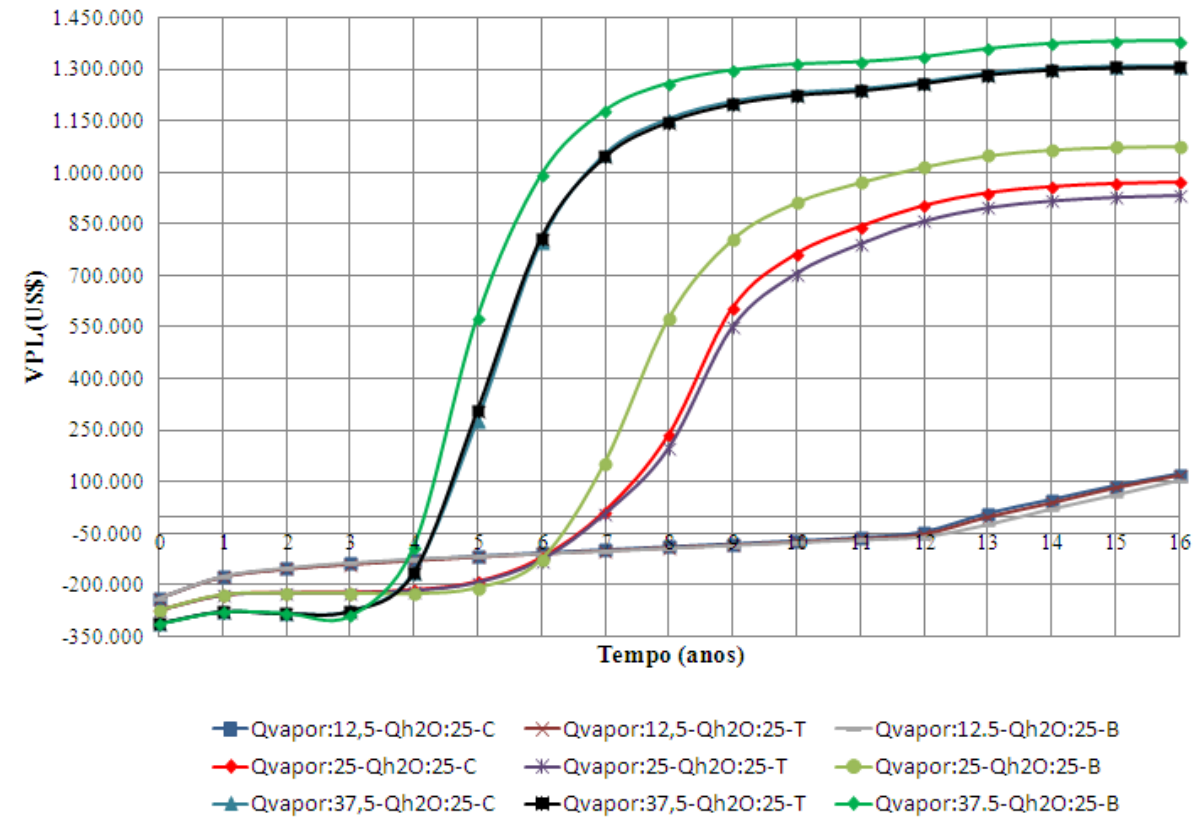

Figura 4. Valor Presente Líquido versus tempo para injeção da água após o vapor.

Com relação ao conjunto de curvas de vazão de vapor 37,5 t/dia, nota-se ainda uma subdivisão em 2 grupos: quando o canhoneio se deu na base e as outras duas formas de canhoneio. O melhor resultado foi obtido no modelo Qvapor:37,5-Qh2O:25-B resultando em um VPL de US\$1.382.156,91. 
Analisando o grupo de curvas onde a vazão de vapor foi de 25 t/dia, percebe que há uma divisão em 3 curvas, determinados pelo canhoneio adotado. O melhor resultado foi de US\$1.080.219,85 para o modelo Qvapor:25-Qh2O:12.5-B. Já para a vazão de 12,5 t/dia o melhor resultado encontrado foi de US\$155.703,30 para o caso Qvapor:12,5-Qh2O:37,5-B.

Para a configuração operacional $\mathrm{Q}_{\text {vapor }}: 37,5-\mathrm{Q}_{\mathrm{h} 20}: 25-\mathrm{B}$ onde o vapor é injetado na base da zona de óleo, percebe-se que a curva ascende primeiro em relação aos outros dois casos, indicando que o banco de óleo chegou mais rápido ao poço produtor. Isto reflete no VPL onde foi obtido US\$1.382.156,91, resultado 5,86\% melhor do que quando se injetou em toda zona de óleo (US\$1.305.611,42) e 5,68\% melhor do que o caso onde se injetou no centro da zona de óleo (US\$1.307.819,79).

A Figura 5 apresenta um comparativo entre mapas de perda de calor para a camada sobrejacente entre a injeção de vapor na base e em toda zona de óleo do reservatório, ao final do quinto ano de projeto para a vazão de vapor de 37,5 t/dia.


Figura 5. Mapas da taxa de perda de calor para a camada sobrejacente (Btu/dia) - Injeção de vapor na base e em todo intervalo da zona de óleo- $5^{\circ}$ ano de projeto.

De acordo com os mapas de perda de calor nota-se uma maior área de perda de energia quando se injeta em todo intervalo da zona de óleo, em virtude da proximidade dos canhoneados em relação à camada sobrejacente. Percebe-se também que a intensidade da taxa de perda em Btu/dia, para este caso, também é maior como mostra a escala mostrada na Figura 5.

De acordo com a análise da configuração operacional base e a variação destes parâmetros percebe-se que o sucesso da injeção de água após o vapor não está ligado ao tempo que este fluido foi inserido e sim a partir de que volume ele é inserido. Quanto maior a vazão de vapor, mais volume é injetado por unidade de tempo e mais cedo deverá começar a injeção de água. Diante disto, o tempo de parada de vapor no $11^{\circ}$ ano de projeto está relacionado à vazão de 25 
t/dia, mas para a de 37,5 t/dia (vazão que apresentou os modelos de maior rentabilidade) o tempo deve ser inferior a este.

\section{CONCLUSÕES}

$>$ Os maiores valores de VPL foram obtidos para elevadas vazões de injeção de vapor e qualquer nível de injeção de água.

As melhores respostas de VPL foram obtidas para elevadas vazões de injeção de vapor e completação na base do reservatório;

Para a vazão de injeção de 37,5 t/dia têm-se o menor tempo de retorno do investimento, ocorrendo entre o $4^{\circ}$ e $5^{\circ}$ ano de projeto;

O modelo otimizado obtido foi vazão de injeção 37,5 t/dia, vazão de água 25 m²/dia e completação na base do reservatório obtendo um VPL de US\$1.382.156,91.

Quando se injeta na base do reservatório há uma menor perda de calor em relação às outras duas completações analisadas, acarretando em uma maior eficiência térmica. Por este fato, há uma pequena antecipação na produção do banco de óleo aquecido.

Percebeu-se que o êxito da injeção de água após o vapor não está no tempo em que ele é inserido no sistema, mas sim a partir de que volume é injetado visto que quanto maior a vazão, mais cedo à água deverá ser injetada.

\section{AGRADECIMENTOS}

Os autores gostariam de agradecer ao PRH-221 da Petrobras, ao PRH-43 da ANP e ao Laboratório de Estudos Avançados em Petróleo (LEAP - UFRN) por todo o suporte fornecido para a execução deste trabalho.

\section{REFERÊNCIAS}

Galvão, E. R. V. P. Injeção de vapor e solvente como método de recuperação avançada em reservatório de óleo pesado. 2008. 106 f. Dissertação (Mestrado em Engenharia de petróleo) Centro de Tecnologia, Programa de Pós-Graduação em Ciência e Engenharia de Petróleo, Universidade Federal do Rio Grande do Norte, Natal.

Rodrigues, M. A. F. Análise de viabilidade de injeção de fluidos alternativos ao vapor em reservatórios de óleo pesado. 209 f. Tese (Doutorado em Engenharia de petróleo) - Centro de Tecnologia, Programa de Pós-Graduação em Ciência e Engenharia de Petróleo, Universidade Federal do Rio Grande do Norte, Natal. 